\title{
Is Fear a Factor in Voles? Short Term Physiological and Behavioural Response to Predation Stress
}

\author{
Lenka Trebatická $^{1,2}$, Tarmo Ketola ${ }^{2}$, Marko Haapakoski ${ }^{1}$, Annika Opperbeck ${ }^{1}$ and Hannu Ylönen ${ }^{*}, 1,2$ \\ ${ }^{I}$ Konnevesi Research Station, Department of Biological and Environmental Science, P. O. Box 35, FI-40014 University \\ of Jyväskylä, Finland \\ ${ }^{2}$ Department of Biological and Environmental Science, P. O. Box 35, FI-40014 University of Jyväskylä, Finland
}

\begin{abstract}
A predator has a large impact on its prey. Besides a direct lethal effect, mere predator presence can increase stress and vigilance reflecting on prey behaviour and physiology. Such an effect should be stronger in more vulnerable prey individuals, depending e.g. on sex and reproductive status. We studied the short-term physiological response, the change in $\mathrm{CO}_{2}$ production as a measure of metabolism, and the behavioural response in non-pregnant and pregnant bank vole Myodes glareolus females. The bank vole is a common small mammal in boreal forest environments and one of the major prey species for predators, especially small mustelids. The least weasel Mustela nivalis nivalis is a vole specialist and the only predator which can enter the tunnels of voles and their nests. Furthermore, weasels, like all mustelids, have strong scents used in social communication, and weasel odour may be used as a cue of increased risk by prey individuals. We simulated an increase in predation risk by the injection of least weasel odour into an open-flow respirometry system housing either a pregnant or non-pregnant female bank vole. We focused on immediate and post-stress response in $\mathrm{CO}_{2}$ production and changes in female behaviour. We found that injections of pure air ("disturbance") or of weasel odour ("threat") similarly increased $\mathrm{CO}_{2}$ production. Surprisingly, non-pregnant females responded to stress more strongly than pregnant ones, i.e. the increase in $\mathrm{CO}_{2}$ was higher. Weasel odour increased female activity more than the injection of air. According to our prediction, after the disappearance of weasel odour there were no differences in physiological or behavioural parameters between pregnant and non-pregnant females. Contrary to our prediction, our results showed quite similar response to harmless air disturbance and the risky weasel cue. However, it may be that in a situation of sudden change in environment, regardless of its nature, a short-term vigilance response is a better response than more costly antipredatory behaviours.
\end{abstract}

Keywords: Energy, fear, predation, prey, stress, vole, weasel.

\section{INTRODUCTION}

Predators play essential and often complex roles in regulating communities. Besides killing their prey, predators can affect them by their mere presence (Brown et al. 1999). Both the presence of predators and indirect cues of their presence can induce changes in prey morphology, physiology, behavior and life history traits, affecting prey's lifetime fitness and subsequently population dynamics and community structure (Woodley \& Peterson 2003). On a population level non-lethal effects (fear) might often be as large as, or larger than, the effects of a predator killing its prey (Preisser et al. 2005, Luttbeg \& Kerby 2005).

Physiologically mediated life-history responses to threat (Brown et al. 1999, Ylönen \& Brown 2007) may include changes in plasma levels of corticosteron concentration (Scheuerlein et al. 2001), a symptom of stress in various species (Siegel 1980, Eilam et al. 1999). In addition, induction of stress proteins has been demonstrated under the risk of predation in a variety of species (Kagawa et al. 1999,

*Address correspondence to this author at the Konnevesi Research Station, Department of Biological and Environmental Science, P. O. Box 35, FI40014 University of Jyväskylä, Finland; Tel: +358-14-2602250; Fax: +35814-2602291; E-mail: hannu.j.ylonen@jyu.fi

Special Issue Editor: John W. Laundré
Pauwels et al. 2007, Slos \& Stocks 2008). As a response to increased need for stress proteins, an increase of energy consumption has also been observed (Woodley \& Peterson 2003, Beckerman et al. 2007, Slos \& Stocks 2008), which in turn could be linked to predator-induced growth reduction (Slos \& Stocks 2008).

Behaviorally mediated life-history responses to predation threat are the most profound way to avoid predation. Behavioral responses towards predators include changes in overall activity, shifts in microhabitat use, and escape reactions (see Lima \& Dill 1990, Norrdahl \& Korpimäki 1995, Ylönen \& Brown 2007 for review). Two opposite antipredatory behavioral reaction patterns exist, "fleeing" and "freezing". It seems that these two are phenotypically flexible response patterns, for instance in voles (Sundell \& Ylönen 2004), and after a correct stimulus interpretation both may be equally effective for survival, depending on type of predator and hunting environment (Eilam et al. 1999). An unfamiliar environment or a previous aversive event can, however, alter the balance between these behaviors (Mongeau et al. 2003). The intermediate behaviors should be the most ineffective against an approaching predator. Since the fear reactions change behavior from normal, the prey can suffer effects on individual fitness due to reductions of time spent for foraging and reproduction 
(e.g. Brown et al. 1992, Scheuerlein et al. 2001). Therefore, fitness under predation risk is a function of resource allocation on reproduction, foraging, and antipredatory behaviors. Prey response should be effective, immediate and short-term, the greatest during the brief pulse of high risk and the lowest during the pulses of safety, as predicted by the "risk allocation hypothesis" (Lima \& Bednekoff 1999).

Here we report a study exploring the effect of an indirect predator cue, predator odour, on the energy use and behavior of non-pregnant or pregnant bank vole females. We used the least weasel Mustela nivalis nivalis odour as the predator cue as it is known that rodent prey may use mammalian predator odour as a cue for increased predation risk (Ylönen 2001). Further, least weasel is the only "snake-like" predator which can enter the rodent world, their tunnel systems and nests, and leave there their specific "business card" in form of strong social scent. We hypothesized that the greatest response on physiology and behavior is found after exposing females to weasel odour, in comparison to a control of pure outside air. Moreover, it has been proposed that especially small mammal females in oestrus (Cushing 1985) are more prone to mammalian predation. In addition to behavioral changes associated with reproduction, the females encumbered by the pregnancy and being less motile, should have an increased response to weasel odour, compared to nonpregnant females.

\section{METHODS}

\section{Study Animals}

The bank vole Myodes glareolus, is a common boreal rodent with a promiscuous mating system (Klemme et al. 2008). Females normally breed in post-partum oestrus, so they can mate again within a few hours after parturition. We used wild voles, trapped in the Konnevesi region $\left(62^{\circ} 37^{\prime} \mathrm{N}\right.$, $26^{\circ} 20^{\prime} \mathrm{E}$ ), and maintained in the laboratory for six months. Prior to the experiment voles were housed singly in standard mouse cages of $43 \times 26 \times 15 \mathrm{~cm}$ and maintained in a $16 \mathrm{~L}: 8 \mathrm{D}$ light:dark periodicity with a constant temperature of $+20^{\circ} \mathrm{C}$. Water and food (mice pellets) were provided ad libitum.

The least weasel, is a specialist predator of voles in Fennoscandia (Korpimäki et al. 1991) and highly adapted to hunting small rodents in their natural boreal environment (burrows, tunnels, sub-nivean space). It leaves practically no refuge for the prey (Simms 1979, but see Sundell \& Nordahl 2002). Weasel risk in nature is fluctuating and different between years (Korpimäki et al. 1991). Seasonally the risk differs in that in spring and early summer there are less weasels in numbers, but all are old and experienced. Also, energy need of breeding female weasels increases their hunting effort and thus spring - early summer per capita risk for voles, albeit low in numbers, is high. Weasels were fed dead bank voles prior to the experiment and housed singly in large plexi-glass cages (each of $60 \times 80 \times 60 \mathrm{~cm}$ ) with a mesh wire cover.

\section{Respirometry}

Measurements of the metabolic rate $\mathrm{ml} \mathrm{CO}_{2} \mathrm{~h}^{-1}$ were made at room temperature $\left(22^{\circ} \mathrm{C}\right)$. The carbon dioxide production was measured with a $\mathrm{CO}_{2}$ analyzer (LI-6251, LI-
COR, Lincoln, Nebraska, USA) connected to Datacan V data acquisition and analysis software (Sable Systems Inc., Las Vegas, Nevada, USA). Prior to entering the respirometry chamber, the incoming air was filtered through silica gel and soda lime, so that moisture and $\mathrm{CO}_{2}$ were removed. The steady flow rate of $1.51 \mathrm{~min}^{-1}$ to the measurement chamber (volume $538 \mathrm{~cm}^{3}$ ) was regulated by a mass-flow controller (Sierra Instruments, Monterey, California, USA). The air containing $\mathrm{CO}_{2}$ produced by females passed through a small drierite column to the $\mathrm{CO}_{2}$ analyser. Data were recorded every second and analysed by Datacan V software.

\section{Study Procedure}

Thirty-six non-pregnant bank vole females were measured for $\mathrm{CO}_{2}$ production under predator and control air environments and their behaviors were recorded. Immediately after the measurements, females were paired with males. A fertile male was put into the female's cage for 5 days. Nine females became pregnant and a second measurement of these animals was conducted 20 days later. Females were weighed before both measurements. During each measurement, a female was placed into a cylindrical plastic chamber with airtight lids at both ends. A wire mesh basket was placed close to the outlet to prevent that the animals exhale close to the outlet. The $\mathrm{CO}_{2}$ production was measured altogether for 110 minutes: 5 min of baseline (without a vole), $30 \mathrm{~min}$ of habituation, $30 \mathrm{~min}$ of resting metabolic rate, $40 \mathrm{~min}$ of treatment and $5 \mathrm{~min}$ of baseline in the chamber. We used a 2-min interval of lowest values to calculate the mean $\mathrm{CO}_{2}$ production during the resting metabolic time. During the 40 min of treatment we injected $60 \mathrm{ml}$ of pure air twice into the chamber (hereafter: $\mathrm{alb}=$ before the first air injection, ala = after the first injection, $\mathrm{a} 2 \mathrm{~b}$ and $\mathrm{a} 2 \mathrm{a}=$ before and after second air injection), and after that twice $60 \mathrm{ml}$ of weasel odour (w1b and $\mathrm{wla}=$ before and after first weasel odour injection, w2b and w2a $=$ before and after second weasel odour injection), always in 10 min intervals. The whole measurement was stopped after the final $5 \mathrm{~min}$ of baseline. The chamber was placed into a box with an infrared camera system in order to monitor the activity of females. Different activity modes were recorded. Sleeping was considered as inactivity and moving, biting, climbing, sniffing and licking as modes of activity. After each measurement the chamber was rinsed with water and dried. Measurements were made between 0800 and 2100 . Weasel odour was obtained from a tightly closed one litre plastic bag containing weasel faeces, which were collected, frozen and subsequently let thawed the night before the particular measurements.

\section{Data and Statistical Analyses}

First, we examined the immediate response to short-term predation risk. We calculated the mean $\mathrm{CO}_{2}$ production over 2 minutes before injection and after injection, regardless of pure air or weasel odour. The first 30 seconds before and after injection were always excluded from the analyses due to the time delay between injection of the syringe content and response. Only a 2 min-interval after that was used in the analysis. Since the weasel odour itself contained $\mathrm{CO}_{2}$, we subtracted on average $5.06 \mathrm{ml} \mathrm{h}^{-1}$ of $\mathrm{CO}_{2}$ from the mean values after injection, in case of weasel odour injection. The 
subtracted value was based on five measurements of $\mathrm{CO}_{2}$ content in a syringe with weasel odour, without a vole in a system. The method of calculation was the same as in the case of "vole" $\mathrm{CO}_{2}$ production. Secondly, we focused on the reaction of females, in terms of $\mathrm{CO}_{2}$ production, after removal of weasel odour from the system. Therefore, we calculated the mean production of $\mathrm{CO}_{2}$ before injection as in the first case, however, after injection we did not take into consideration the first $210 \mathrm{~s}$ (30 s of delay and $180 \mathrm{~s}$ of weasel odour removal) but the following 2 minutes. In case of pure air, we followed the same procedure.

We calculated the differences for air and for weasel odour, as a1a-a1b, a2a-a2b, w1a-w1b and w2a-w2b. These differences were used in the statistical analyses. We used GLIMMIX to analyze the effect of female status (nonpregnant or pregnant), treatment (air or weasel odour) and their interaction on the after-before differences in $\mathrm{CO}_{2}$ production. Before stress $\mathrm{CO}_{2}$ values (values before injections) were used as covariates, the response distribution was Gaussian with an identity link function. We included two random effects in the model: (1) identity of an individual on intercept and (2) measurement nested within an individual on both intercept and the treatment effect. Degrees of freedom were calculated by the Kenward-Roger method.

Regarding behavioral data, we measured activity concurrent to $\mathrm{CO}_{2}$ measurements as the proportion of time the female was active (moving, biting, climbing, sniffing and licking) over 3 minutes before and after injection. The rest of the time the female was inactive (sleeping). In another GLIMMIX model, we assessed the effects of pregnancy (variable state) and treatment (air and weasel odour) and its interaction on activity after injections. Binomial error distribution and a logit link function were used. We used two random factors: 1) the random effect of identity of an individual on intercept and (2) random effect of repeated measurements within an individual (a series of 4 trials denoted a1, a2, w1, w2), with first order autoregressive covariance structure. We used proportion activity before injections as an offset variable. All statistical analyses were performed using SAS 9.1 (SAS Institute Inc. 2004).

\section{RESULTS}

We did not find a difference in the immediate response to either disturbance or threat, i.e. pure air or weasel odour injections (treatment: $\mathrm{F}_{1,68}=0.13, p=0.715$ ). In both cases, females elevated $\mathrm{CO}_{2}$ production after the injection (Fig. 1A). However, there was a difference in response to stress (joint disturbance and threat effect) between non-pregnant and pregnant females (status: $\mathrm{F}_{1,48}=4.87, p=0.032$ ). Nonpregnant females increased $\mathrm{CO}_{2}$ production much more after injections than pregnant ones (Fig. 1A). This result vanished (status: $\mathrm{F}_{1,51}=0.33, p=0.571$ ), after consideration of before stress values in an analysis as a covariate (covariate: $\mathrm{F}_{1,254}=$ $146.32, p<0.001$ ). However, it only means that the different

\section{A. Immediate response}
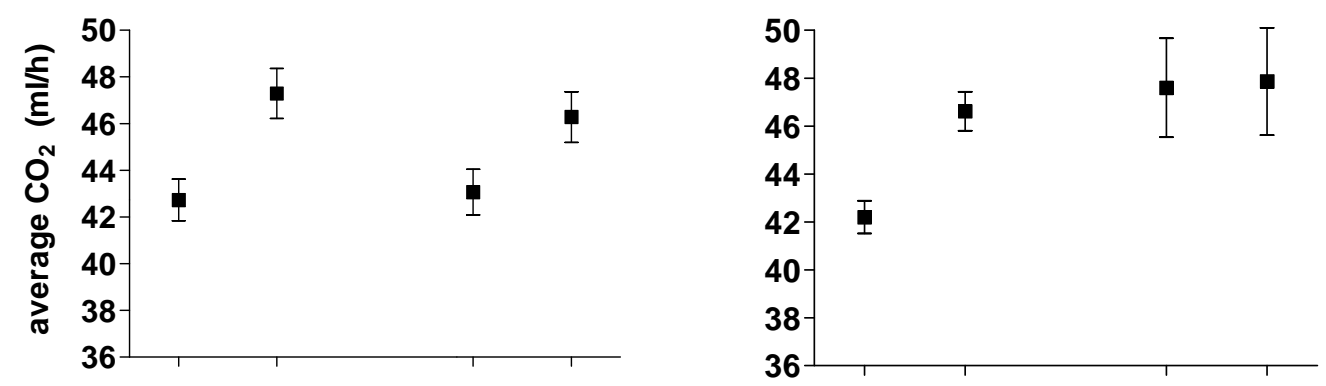

\section{B. After stress response}
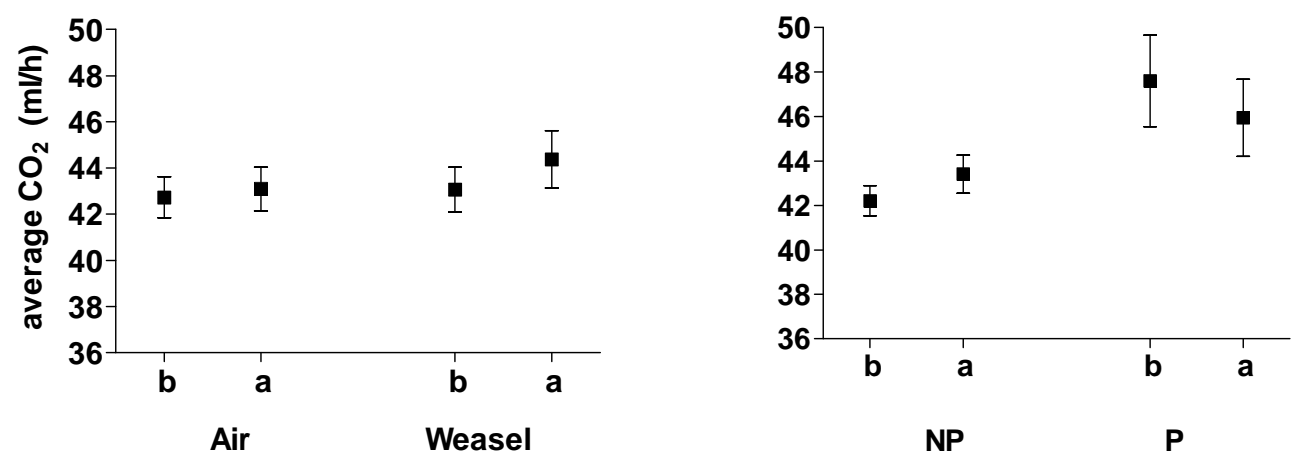

Fig. (1). The average production of $\left.\mathrm{CO}_{2} \mathbf{A}\right)$ as immediate response to injections of air and weasel odour. $\mathrm{CO}_{2}$ production before (b) and after (a) injection and in non-pregnant (NP) and pregnant (P) females. B) $\mathrm{CO}_{2}$ production during the after stress phase. Legends are the same like in panel A. Error bars denote SEM. 
response in non-pregnant and pregnant females was due to lower $\mathrm{CO}_{2}$ production in non-pregnant females before stress was induced. This effect occurred for pure air or weasel odour (status*treatment: $\mathrm{F}_{1,68}=1.78, p=0.186$ ).

After the weasel odour had disappeared from the system (post-stress response), the metabolic response also vanished and differences between different reproductive statuses disappeared (status: $\mathrm{F}_{1,68}=0.91, p=0.343$ ). Although the effect of the covariate (before stress values) was significant (covariate: $\mathrm{F}_{1,273}=370.40, p<0.001$ ), still no differences between non-pregnant and pregnant females were found (Fig. 1B, status: $F_{1,62}=3.62, p=0.062$ ). No dissimilarity between disturbance and threat was found (Fig. 1B, treatment: $\mathrm{F}_{1,201}=0.04, p=0.847$ ).

Behaviorally, females were more active after injections of the weasel odour (treatment: $\mathrm{F}_{1,193}=4.23, p=0.041$ ), though females responded to both, disturbance and threat by higher activity (Fig. 2). There were no differences in activity between non-pregnant and pregnant females (status: $\mathrm{F}_{1,75}=$ $0.34, p=0.561)$. No effect of treatment by status interaction was found $\left(\mathrm{F}_{1,193}=0.04, p=0.851\right)$.

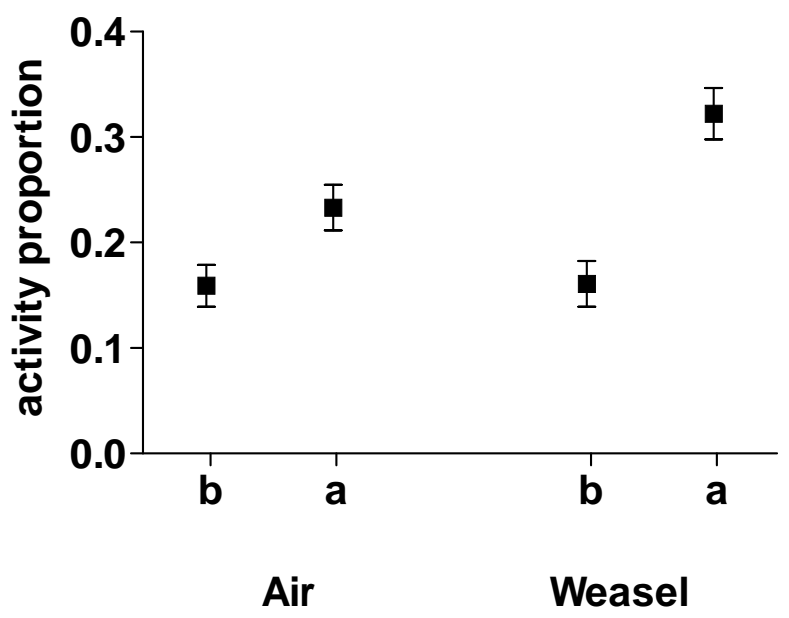

Fig. (2). The changes in activity after injections, i.e. the proportion of being active before (b) and after (a) induced stress. Error bars denote SEM.

\section{DISCUSSION}

We performed an experiment in which we explored an immediate physiological and behavioral response to shortterm stress (disturbance and threat) in female voles of different reproductive status. We also examined the poststress physiological response. We predicted a stronger response in pregnant females as they are supposed to be more prone to mammalian predation, especially by the least weasel (Jedrzejewski et al. 2003). We found that females responded to both disturbance and weasel threat similarly by elevation of $\mathrm{CO}_{2}$ production. This response to stress was stronger in non-pregnant females compared to pregnant ones. The immediate response differed from the post-stress response where no metabolic response was found between female groups. Behaviorally, females responded to threat with higher activity than to disturbance.
Regarding the immediate reaction to short-term stress it would appear that females were not able to distinguish a predation threat from a general disturbance, since they responded similarly to both control air and weasel odour. This would appear to be a surprising result as predator scents have been shown to represent a clear indirect cue for increased predation risk in many studies, especially those carried out in the laboratory (Ylönen 2001, Apfelbach et al. 2005). The least weasel has also been shown to be the main mortality factor of voles in the field (Norrdahl \& Korpimäki 2000). Further, in a recent study Mönkkönen et al. (2009) showed that passerine birds, generally regarded to have a less developed olfactory system, also can assess spatial and temporal variation in predation risk based on olfactory cues of mammalian predators, particularly weasel odour. However, in all of these studies the response was a more long-term behavioral change or involved decision making. In contrast, our study focused on the initial and short-term response to a disturbance and a threat. Our result is more in concordance with a general initial response to a disturbance, which may or may not include predation threat. In terms of metabolism, the general initial response to a disturbance is an increase in oxygen consumption from elevated respiration (Woodley \& Peterson 2003, Beckerman et al. 2007). Thus, we suggest that in this short-term response, the increase in the vigilance response pays off for any disturbance, threat or benign. After this initial response, the vole can then decide if more action is needed. This was supported by the behavioral data where, given a slightly longer time, voles responded with increased activity to the threat stimulus.

We found a stronger physiological response to stress (regardless of treatment) in non-pregnant than in pregnant females. However, this result may be due to different beforestress $\mathrm{CO}_{2}$ production between both groups, i.e. lower $\mathrm{CO}_{2}$ production in non-pregnant females before injections. This is in concordance with findings that show elevated metabolic rate in females (oxygen consumption, e.g. Speakman \& McQueenie 1996, Johnson et al. 2001) during pregnancy, although our own findings point out that pregnancy alone does not necessarily increase the metabolic rate of a female (Trebatická et al. 2007). It is possible the higher $\mathrm{CO}_{2}$ production in pregnant females indicates a general higher stress level in this group during the experiments, e.g. females became more vigilant when pregnant. In this case, it is possible that pregnant females did not show a physiological response to either air or weasel odour because they might have been at their physiological limitation. There is evidence that individuals are found to not increase energy use over certain limits (see Speakman \& Król 2005, for review). Therefore, it could be speculated that already high energy use by pregnant females in this study was reaching a limit above which another greater increase was not possible. The observed increase in activity in both groups supports this possibility because it indicates that both responded behaviorally to the threat stimulus. The fact that both groups responded similarly may indicate that all females viewed the threat of predation equally, regardless of their reproductive status.

We explored also after-stress physiological changes, expecting that our manipulation would cause a short-term 
response, especially a possible return of the physiological or behavioral status of the experimental female after removal of the weasel odour from the system was of interest. As expected, any difference between females of a different reproductive status found during the immediate response disappeared. The dissimilarity found between immediate and post-stress response could suggest that females after immediate stress do not continue keeping up the antipredatory behavior as it is too costly (Lima \& Dill 1990). This is also in concordance with Lima and Bednekoff's (1999) model of the "risk allocation hypothesis" that the prey response should be greatest during the brief pulse of risk and lowest during the following pulses of safety.

To conclude, we found both a physiological and a behavioral response to short-term stress, regardless if it was caused by disturbance only or by a threat cue. We found slight increase in $\mathrm{CO}_{2}$ production and a more pronounced threat effect on activity. Surprisingly, the female responses to both the weasel odour and to control air were similar. We propose, that it may pay always to increase vigilance after a disturbance and later assess the different severity of sole disturbance or threat. It seemed that the pregnant females' response was not as strong, which might indicate that in this reproductive state, keeping as silent and invisibly as possible is the better option than fleeing and leaving acoustic and olfactory cues for the possibly following predator. As the number of pregnant females was low, the possible differences in behavior or antipredatory strategies between nonbreeding and heavier and possibly clumsier pregnant females need further experimental verification. The return of physiological and behavioral status after disturbance and threat pulse could represent an adaptation to short-term stress and the length of disturbance pulse.

\section{ACKNOWLEDGEMENTS}

We thank the staff of the Konnevesi Research Station for technical support and help in maintenance of experimental animals and Erkki Korpimäki and Jens Jacob for valuable comments. The study was supported by the University of Jyväskylä (LT), by the Academy of Finland (TK, HY), Ella and Georg Ehrnrooth Foundation (TK), Finnish Cultural Foundation $(\mathrm{MH})$ and CIMO (AO).

\section{REFERENCES}

Apfelbach, R, Blanchard, CD, Blanchard, RJ, Hayes, RA \& McGregor, IS (2005) The effects of predator odors in mammalian prey species: a review of field and laboratory studies. Neuroscience and Biobehavioral Reviews, 29, 1123-44.

Beckerman, AP, Wieski, K \& Baird, DJ (2007) Behavioural versus physiological mediation of life history under predation risk. Oecologia, 152, 335-43.

Brown, JS, Morgan, RA \& Dow, BD (1992) Patch use under predation risk: II. A test with fox squirrels, Sciurus niger. Annales Zoologici Fennici, 29, 311-18.

Brown JS, Laundre, JW \& Gurung, M (1999) The ecology of fear: optimal foraging, game theory and trophic interactions. Journal of Mammalogy 80, 385-99.

Cushing, BS (1985) Estrus mice and vulnerability to weasel predation. Ecology, 66, 1976-78.

Eilam, D, Dayan, T, Ben-Eliyahu, S, Schulman, I, Shefer, G \& Hendrie, CA (1999) Differential behavioural and hormonal responses of voles and spiny mice to owl calls. Animal Behavior, 58, 1085-93.
Jedrzejewski, W, Rychlik, L \& Jedrzejewska, B (1993) Responses of bank voles to odours of seven species of predators: experimental data and their relevance to natural predator vole relationships. Oikos, 68, 251-57.

Johnson, MS, Thomson, SC \& Speakman, JR (2001) Limits to sustained energy intake. III. Effects of concurrent pregnancy and lactation in Mus musculus. Journal of Experimental Biology, 204, 1947-56.

Kagawa, N, Ryo, K \& Mugiya, Y (1999) Enhanced expression of stress protein 70 in the brains of goldfish, Carassius auratus, reared with bluegills, Lepomis macrochirus. Fish Physiology and Biochemistry, 21, 103-110.

Klemme, I, Ylönen, H \& Eccard, JA (2008) Long term fitness benefits of polyandry in a small mammal, the bank vole Clethrionomys glareolus. Proceedings of Royal Society London B, 275, 10951100 .

Korpimäki, E, Norrdahl, K \& Rinta-Jaskari, T (1991) Responses of stoats and least weasels to fluctuating vole abundances: is the low phase of the vole cycle due to mustelid predation? Oecologia, 88, 552-61.

Lima, SL \& Bednekoff, PA (1999) Temporal variation in danger drives antipredator behavior: the predation risk allocation hypothesis. American Naturalist, 153, 549-659.

Lima, SL \& Dill, LM (1990) Behavioural decision made under the risk of predation: a review and prospectus. Canadian Journal of Zoology, $68,619-40$.

Luttbeg, B \& Kerby, JL (2005) Are scared prey as good as dead? Trends in Ecology and Evolution, 20, 416-18.

Mongeau, R, Miller, GA, Chiang, E \& Anderson, DJ (2003) Neural correlates of competing fear behaviours evoked by an innately aversive stimulus. Journal of Neuroscience, 23, 3855-68.

Mönkkönen, M, Forsman, JT, Kananoja, T \& Ylönen, H (2009) Indirect cues of nest predation risk and avian reproductive decisions. Biology Letters, DOI: 10.1098/rsbl.2008.0631.

Norrdahl, K \& Korpimäki, E (1995) Mortality factors in a cyclic vole population. Proceedings of the Royal Society of London B, 261, 4953 .

Norrdahl, K \& Korpimäki, E (2000) The impact of predation risk from small mustelids on prey populations. Mammal Review, 30, 147-56.

Pauwels, K, Stocks, R, Decaestecker, E \& De Meester, L (2007) Evolution of heat shock protein expression in a natural population of Daphnia magna. American Naturalist, 170, 800-5.

Preisser, EL, Bolnick, DI \& Bernard, MF (2005) Scared to death? The effects of intimidation and consumption in predator-prey interactions. Ecology, 86, 501-9.

Scheuerlein, A, Van't Hof, TJ \& Gwinner, E (2001) Predators as stressors? Physiological and reproductive consequences of predation risk in tropical stonechats (Saxicola torquata axillaries). Proceedings of Royal Society London B, 268, 1575-82.

Siegel, HS (1980) Physiological stress in birds. Bioscience, 30, 529-34.

Simms, DA (1979) North American weasels: resource utilization and distribution. Canadian Journal of Zoology, 57, 504-20.

Slos, S \& Stoks, R (2008) Predation risk induces stress proteins and reduces antioxidant defence. Functional Ecology, 22, 637-42.

Speakman, JR \& Król, E (2005) Limits to sustained energy intake IX: a review of hypotheses. Journal of Comparative Physiology B., 175 , 375-94.

Speakman, JR \& McQueenie, J (1996) Limits to sustained metabolic rate: The link between food intake, basal metabolic rate and morphology in reproducing mice, Mus musculus. Physiological Zoology 69, 746-69.

Sundell, J \& Norrdahl, K (2002) Body size dependent refuges in voles: an alternative explanation of the Chitty effect. Annales Zoologici Fennici, 39, 325-33

Sundell, J \& Ylönen, H (2004) Behaviour and choice of refuge by voles under predation risk. Behavioural Ecology and Sociobiology, 56, 263-69

Trebatická, L, Ketola, T, Klemme, I, Eccard, JA \& Ylönen, H (2007) Is reproduction really costly? Energy metabolism of bank vole (Clethrionomys glareolus) females through the reproductive cycle. Écoscience, 14, 306-13.

Woodley, CHM \& Peterson, MS (2003) Measuring responses to simulated predation threat using behavioural and physiological metrics: the role of aquatic vegetation. Behavioral Ecology, 136, 155-60.

Ylönen, H (2001) Predator odours and behavioural responses of small rodents: an evolutionary perspective. In: Pelz, H-J, Cowan, PD \& 
Feare, CJ. (Eds) Advances in Vertebrate Pest Management II, Filander: Fuerth 123-38.

Ylönen, H \& Brown, JS (2007) Fear and the foraging, breeding and sociality in rodents. In: Wolff JO and Sherman PW (Eds), Rodent societies:
An Ecological and Evolutionary Perspective. University of Chicago Press: Chicago 328-41.

Received: December 09, 2009

Revised: June 02,2010

Accepted: July 02,2010

(C) Trebatická et al.; Licensee Bentham Open.

This is an open access article licensed under the terms of the Creative Commons Attribution Non-Commercial License (http://creativecommons.org/licenses/by$\mathrm{nc} / 3.0 /$ ), which permits unrestricted, non-commercial use, distribution \& reproduction in any medium, provided the work is properly cited. 